Article

\title{
Sea-Water Desalination for Load Levelling of Gen-Sets in Small Off-Grid Islands
}

\author{
Alessandro Corsini ${ }^{1}$ (i) and Eileen Tortora ${ }^{2, *}$ \\ 1 Department of Mechanical and Aerospace Engineering, Sapienza Università di Roma, via Eudossiana 18, \\ 00184 Roma, Italy; alessandro.corsini@uniroma1.it \\ 2 Faculty of Civil and Industrial Engineering, Sapienza Università di Roma, via Andrea Doria 3, \\ 04100 Latina, Italy \\ * Correspondence: eileen.tortora@uniroma1.it; Tel.: +39-077-347-6521
}

Received: 20 June 2018; Accepted: 2 August 2018; Published: 8 August 2018

check for updates

\begin{abstract}
This study deals with the energy/water nexus on small off-grid islands. Small islands share several characteristics that hinder the introduction of new plants, such as: Energy system balance when renewable sources are introduced; water shortages, usually addressed via shipping from the mainland; environmental and historical heritage values; and, scarce land availability. In these cases, it is mandatory to detect energy/water technology integration and management solutions respecting the peculiarities and boundaries of the sites. The present work proposes a desalination plant with a primary scope of load leveler and a secondary scope of water producer. The aim is to propose a simple and non-invasive solution for energy/water management in order to limit impacts on the local environment while improving the match between renewable energy and local generation by means of desalination. This study led to an integrated system composed of local diesel engine power plant, distributed roof-top photovoltaic plants and a desalination plant, managed by a dedicated control logic. Desalination from renewable energy and power adjustments of already active diesel engines are favored. The case study refers to Ponza island, in the Tyrrhenian Sea. This paper demonstrates the effective possibility of using a desalination plant with the double purpose of water production and load levelling, providing $98 \%$ of the local water demand while mitigating the renewable energy fluctuations effects on the gen-set. Moreover, the proposed system results in a $50 \% \mathrm{CO}_{2 \mathrm{eq}}$ emissions abatement over the current water supply carbon footprint.
\end{abstract}

Keywords: water-energy nexus; island; diesel engine; renewable energy; desalination

\section{Introduction}

Although small islands' energy and water supply problems and solutions have been studied for a long time, high costs are still experienced. A levelized cost of energy of EUR 0.38/kWh [1], in some cases exceeding EUR 0.70/ $\mathrm{kWh}$ [2], and water costs of over EUR $11 / \mathrm{m}^{3}[3,4]$ are related to the usual dependency of the shipping-fuel and water restock. Moreover, demand is often concentrated in the summer period due to island tourism vocation $[3,5,6]$.

In the last decades, islands have been considered as the ideal test-bed for renewable energy penetration, with some successful results [7]. To mention just a few, Meschede et al. [8] classified 1087 islands using cluster analysis allowing the identification of similar islands, in order to foster proven and well-working concepts from one island to others with analogous characteristics. Blechinger et al. [9] assessed the renewable energy source (RES) potential of 1800 small islands, conducing to the estimation of almost 7.5 GW of photovoltaic power and $14 \mathrm{GW}$ of wind power, and a potential greenhouse gas emissions and fuel consumption abatement of approximately 50\%. Gils et al. [10] analyzed the scenario pathway to a $100 \%$ RES supply in the Canary Islands by 2050 . The study highlighted the need to 
extend electric energy use to the mobility, heating and hydrogen production in order to support the integration of a large share of intermittent renewable power generation. Maizi et al. [11] discussed a methodology to forecast the reliability and robustness of an island power grid for a large share of intermittent sources, which jeopardize the consistency of the power supply, aiming at $100 \%$ RES penetration. Other works deal with more technological aspects, proposing different power generation schemes, energy storage and managements solutions, as reviewed by Kuang et al. [12].

Despite the amount of theoretical studies and several international initiatives [13,14], renewable energy penetration is still restricted. Currently, only twenty islands are in transition toward $100 \%$ renewable energy, with ten islands having already reached the goal [15]. In view of the emission limits defined by the European Industrial Emissions Directive for islands prior to 31 December 2019, the use of RES represents a real opportunity to advance energy transition, especially when most European islands are expecting increases in electricity demand, with an average increase of $24 \%$ from 2009 to 2020 (note that the EU-27 increase is expected to be 14\%) [16]. The barriers to fossil-fuel free stand-alone grids lie in the difficulty of managing a highly fluctuating RES power supply, with the risk of worsening the performance of the local diesel generators (also called gen-sets), typically operated at part-load. Moreover, most of the proposed actions to tackle island energy related problems deal with RES in combination with energy storage [15-17]. Nevertheless, the introduction of storage technologies on islands is demanding, mainly because of the significant cost and interoperability difficulties $[18,19]$. Notably, in contexts like the Greek Aegean Islands or Italian minor islands, RES and energy storage technologies introduction is additionally hindered [15,18-20], due to severe environmental restrictions (i.e., the European Directive 2009/147 limits wind generator installation as it represents a disturbing element for bird life and migratory fluxes). The result is a low RES share, which amounts to only $1048 \mathrm{~kW}$ photovoltaic (PV) power and $36.85 \mathrm{~kW}$ wind power in the 19 Italian small islands, in spite of an overall population of 42,568 inhabitants [15].

In this context, a desalination plant represents a relevant additional energy use (generally 4-6 $\mathrm{kWh} / \mathrm{m}^{3}$ for sea water reverse osmosis desalination) for the generally weak islands' energy system. Aiming at security and reliability of the power supply, small islands' green energy transition necessarily has to go through an intermediate phase, in which it is mandatory to sift new approaches to system integration among local gen-sets, renewable sources, storage and water desalination.

The relationship between energy and water has drawn great attention in recent years, aiming at better supporting planning and understanding of potentials, both of policies and technologies [21]. Several studies have tried to couple energy and water problems of islands: (i) aiming at fully renewable energy desalination systems as reviewed in [22-24], or (ii) studying energy/water integrated systems, in which surplus renewable energy with respect to the local load is used for desalination purposes [5]. Suitability of desalination to overcome water shortage problems has already been demonstrated in several applications $[3,25]$, allowing water supply costs to drop (i.e., to less than EUR $4 / \mathrm{m}^{3}$ in the Aegean Archipelago with RES energy feeding [3]). In [26] a nexus framework for energy and water in islands is presented, outlining a roadmap from "full input of energy and water" through "semi-input of energy and water" to "zero input of energy and water", which leads an island's energy and water resources to become gradually independent from the mainland.

The integration of desalination systems usually follows two main approaches: Systems driven either by energy availability or by water production objectives.

Energy availability driven systems are autonomous fully dedicated renewable desalination systems. Aiming at fulfilling water needs, the desalination section should be over-sized in order to absorb most of the renewable power peaks, overcoming low intensity and intermittence of RES [27]. It requires energy storage and a complex design, entailing siting and spacing issues [28]. This case represents a one-way storage, in which the energy is stored as drinkable water [5]. With the appropriate technologies. this approach may lead to two-way storage, in which the desalination plant would import the renewable electric energy needed for the operation but also would act as a storage device and export electricity to the grid acting like a virtual battery [29]. Although on average, renewable energy helps 
to lower water production costs both in RES and diesel-RES configurations [30], literature presents cases, such as [31], in which a reverse osmosis (RO) desalination plant solely relying on renewable energy led to a higher water production cost than an equivalent hybrid system using RES and diesel engines (DEGS) (i.e., $2.4 \mathrm{USD} / \mathrm{m}^{3}$ vs. $1.8 \mathrm{USD} / \mathrm{m}^{3}$ ). Moreover, the most current information on desalination shows that use of renewable energy for desalination has increased from $2 \%$ in 1998 to $23 \%$ in 2016 [32,33], but only $1 \%$ of the global desalination capacity is based on energy from renewable sources [34], demonstrating the strong need for further work in order to assess integration possibilities of desalination and renewable energy plants, and to promote their development.

In water goal driven systems, desalination constantly represents an additional load, usually connected to the local energy grid, fed by a mix of renewable energy, fossil fuel energy and energy storage technologies [3,5]. These systems have higher renewable energy penetration and lower water production costs with respect to the fully autonomous desalination plants [28]. However, new dedicated and complex management systems are needed in order to improve the system stability [35]. In fact, as RES power fluctuations produce modifications of the load curve shape, causing sudden load power drops, diesel generators constrain RES utilization, being unable to lower their output below the minimum load settings predetermined to ensure engine efficiency and preserve engine condition. Thus, during RES energy generation, diesel load set points may produce surplus generation, which must be absorbed via regulating devices such as dump loads or energy storage systems [36]. Moreover, low-load operation results in poor fuel efficiency and increased operation and maintenance cost due to incomplete combustion of fuel during light loads [37]. The result is a system of increased complexity, expense and waste. Regardless of approach, it is not currently feasible to totally eliminate diesel generation within a hybrid power system. Instead, optimal or minimal diesel usage is targeted.

Thus, energy availability driven system appears to be more sustainable but need higher investments in renewable and storage technologies to achieve an affordable water production; on the contrary, water goal driven systems are affordable but impact the system stability and fuel consumption, which is generally making them less environment friendly.

The novelty of the present study precisely relies on the desalination integration approach, with the aim of overcoming the over-sizing and affordability problems of the energy availability driven desalination systems and the stability and fuel consumption issues of the water goal driven desalination systems. Desalination here is mostly driven by the necessity to mitigate the RES fluctuation effects on the local generators' power set-points, activating it when the gen-set performance is beneath a fixed threshold, while assuring the needed water supply.

The desalination integration environment considered in the study is an island energy system based on both renewable and fossil fuel energy. As already stated, energy storage requires too bulky and costly equipment [38] and will not be taken into account.

This study was based on the development of three models of an island energy/water system, with increased complexity, and analyzed by means of the results of hourly transient simulations over a one-year period. A dedicated control logic was developed for the integrated water/energy system management. The desalination plant acquires a twofold role of deferrable energy load and energy storage, depending on the energy plant site working conditions. The study demonstrates the capability of a simple desalination plant integrated in the local power system and operated with a proper control logic, to mitigate the negative effects of the RES fluctuations on the diesel engine generator set (DEGS) while simultaneously producing the needed water supply.

\section{Case Study Description}

The case study is the island of Ponza, in the Pontinian Archipelago, Tyrrhenian Sea, with a surface area of $7.5 \mathrm{~km}^{2}$. The number of inhabitants is remarkably dependent on its touristic vocation, and can range from 4000 in winter to about 55,000 in summer. This circumstance leads to severe issues energy and water system management. Electric energy is supplied by two diesel engine (DEGS) power 
station. Respectively, a main power station of 6.2 MW with four engines, and a peak shaving station with installed power 2.6 MW and two engines, typically operated in summer [39]. The yearly energy demand was approximately $11 \mathrm{GWh}$ /year for 2012 (Table 1), with a maximum power demand peak of about $5 \mathrm{MW}$ in the summer period. In winter, demand amounts to 1-2.5 MW [39]. The climate is typical of that of Mediterranean areas, with mild winters and hot summers. Figure 1 shows solar radiation data for Ponza Island, with the average radiation on horizontal plane varying from $1700 \mathrm{Wh} / \mathrm{m}^{2} /$ day in December, to $7800 \mathrm{Wh} / \mathrm{m}^{2} /$ day in July [40]. Land availability and environmental regulations (i.e., European Council Directive 79/409 on wild bird migratory paths), then, are factors limiting the possibility of dedicated renewable technology installations. To this end, besides energy efficiency and photovoltaic technologies, previous studies assessed the wave-energy potential, both for on-shore [41,42] and near shore devices [43].

Table 1. Monthly distribution of energy and water needs of Ponza Island.

\begin{tabular}{cccc}
\hline Month & $\begin{array}{c}\text { Energy Load, Year 2012 } \\
\text { (MWh/Month) [39] }\end{array}$ & $\begin{array}{c}\text { Fresh Water Need, Year 2015 } \\
\mathbf{( 1 0}^{\mathbf{3}} \mathbf{~ m}^{\mathbf{3}} \mathbf{\text { Month) }} \text { [44] }\end{array}$ & $\begin{array}{c}\text { Water Transportation } \\
\text { Emissions }\left(\mathbf{t}_{\mathbf{C O 2} \mathbf{e q}} \mathbf{)} \text { [43] }\right.\end{array}$ \\
\hline 1 & 694 & 17 & 116 \\
2 & 679 & 17 & 116 \\
3 & 663 & 17 & 116 \\
4 & 712 & 22 & 150 \\
5 & 739 & 38 & 259 \\
6 & 1088 & 45 & 307 \\
7 & 1416 & 70 & 478 \\
8 & 1738 & 75 & 512 \\
9 & 961 & 45 & 307 \\
10 & 643 & 20 & 136 \\
11 & 600 & 17 & 116 \\
12 & 706 & 17 & 116 \\
Total & 10,639 & 400 & 2729 \\
\hline
\end{tabular}

From the water point of view, Ponza is devoid of springs or wells and completely depends on mainland supply. Water demand varies from a $10-40 \mathrm{~m}^{3} / \mathrm{h}$ range in winter to peaks of $240 \mathrm{~m}^{3} / \mathrm{h}$ in summer. The global amount of water supply was $400,000 \mathrm{~m}^{3} /$ year in 2015 (Table 1), with a monthly distribution varying in the $17-75 \times 10^{3} \mathrm{~m}^{3} /$ month range [44]. The water supply entails 237 water tank ship trips to bring water from the mainland, with associated emissions of approximately $2730 \mathrm{t}_{\mathrm{CO} 2 \mathrm{eq}}$ /year. More details about the present water supply may be found in [43]. The water authority for Ponza island is developing a project for a desalination plant, constituted by three reverse osmosis units of globally $165 \mathrm{~kW}$ and $1500 \mathrm{~m}^{3}$ / day fresh water production capacity. The desalination plant will be equipped with a dedicated power generation plant composed of two units of $275 \mathrm{~kW}$ diesel generators [44].

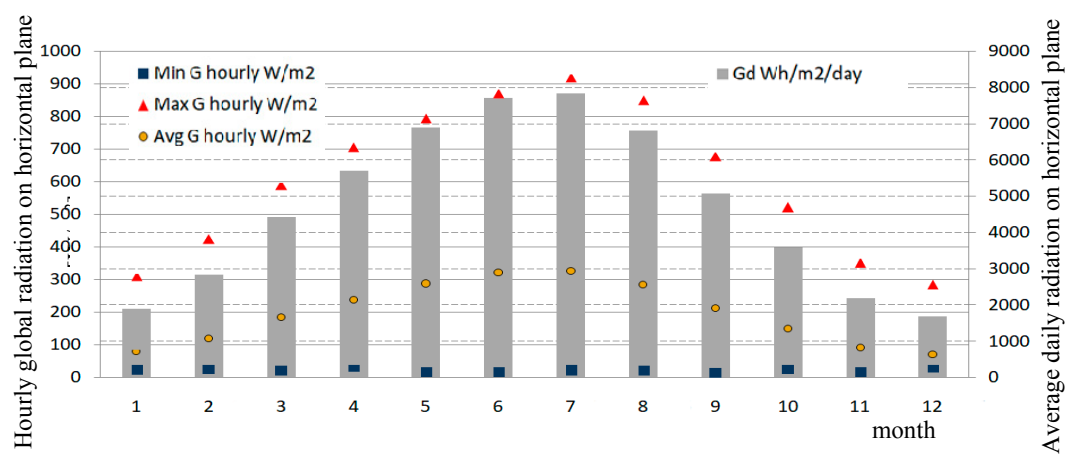

Figure 1. Minimum, maximum and average value for the hourly global radiation on horizontal plane (G-left axis) and average daily radiation on horizontal plane (Gd—right axis) [40]. 


\section{Model Components Description and Data}

The DEGS is modelled by six $1380 \mathrm{~kW}$ units of a CAT $3516 \mathrm{HD}$ engine (Table 2), with a global power of $8.28 \mathrm{MW}$. In accordance with US Department of Energy-National Renewable Energy Laboratory (NREL) [45], it is not recommended for diesel gen-sets to be used under about 20-25\% of their rated capacity, thus the minimum power ratio is set to $280 \mathrm{~kW}$. The reference power is set to $600 \mathrm{~kW}$. The engine efficiency is calculated as the ratio between the output power and the fuel power, which in turn depends on the fuel characteristics (density and low heating value) and the fuel consumption curve of the specific engine with respect to the power set point.

Table 2. Main technologies description.

\begin{tabular}{ccc}
\hline Component & Characteristics & Size \\
\hline DEGS & CAT 3516 HD, six units of $1380 \mathrm{kWp}$ & $8.28 \mathrm{MW}_{\mathrm{p}}$ \\
\hline PV & $\begin{array}{c}10,898 \mathrm{~m}^{2} \text { of roofs } \\
\text { 260 Wp and } 15.8 \% \text { efficiency panels }\end{array}$ & $1.80 \mathrm{MW}_{\mathrm{p}}$ \\
\hline Desalting station & $\begin{array}{c}8 \text { units } \times 300 \mathrm{~m}^{3} / \mathrm{d} \\
\text { Feed flow } 8 \times 32 \mathrm{~m}^{3} / \mathrm{h} \\
\text { Permeate flow } 8 \times 12.5 \mathrm{~m}^{3} / \mathrm{h} \\
\text { Recovery } 40 \%\end{array}$ \\
\hline Water storage & $\begin{array}{c}\text { Global specific energy consumption } 3.6 \mathrm{kWh} / \mathrm{m}^{3} \\
\end{array}$ & $360 \mathrm{~kW}_{\mathrm{p}}$ \\
\hline
\end{tabular}

On the RES generation side, in order to perform a realistic simulation, taking into account environmental restrictions, land availability and economy, the integration of PV plants on private house rooftops has been considered [28]. By means of a geographic information system, an availability of $43,590 \mathrm{~m}^{2}$ of plane rooftops was estimated, without obstructions that may cause shadows, excluding the historical center and the harbor of Ponza town. In the hypothesis of a $25 \%$ share of PV penetration with respect to the surface availability, the resulting global PV power amounts to $1.8 \mathrm{MW}_{\mathrm{p}}$. The selected PV panel has $260 \mathrm{~W}$ peak power with a $15.8 \%$ efficiency in standard conditions. The working conditions hypotheses are: $20^{\circ}$ tilt in order to limit visual impacts and $0^{\circ}$ azimuth. As customary for rooftop PV plants, energy storage devices are not taken into account in the present work.

For the desalination plant, the RO desalination technology has been selected as the state-of-the-art for compact water production units [22]. The modelled system is aimed at completely satisfying the water demand, for which an hourly load curve has been reconstructed leading to a yearly water supply of $420 \times 10^{3} \mathrm{~m}^{3} /$ year. The desalination system size choice has been made trying to merge two essential but opposite aspects: A reduced number of units and a size able to be properly adapted to different values of power availability. The modelled plant will be composed by of eight $300 \mathrm{~m}^{3}$ /day capacity units, a permeate flow of $12.5 \mathrm{~m}^{3} / \mathrm{h} /$ unit and $40 \%$ water recovery. The power consumption of the $\mathrm{RO}$ units, equipped with an energy recovery device, and considering the power request for sea-water draw, fresh water raise and brine rejection, amounts to about $360 \mathrm{~kW}$, with a global specific energy consumption of $3.6 \mathrm{kWh} / \mathrm{m}^{3}$. The local water storage has a cumulative capacity of $3000 \mathrm{~m}^{3}$. The control logic of the water production is aimed at maintaining a $600 \mathrm{~m}^{3}$ level in the storage; i.e., two days autonomy in the winter period.

In order to calculate the equivalent $\mathrm{CO}_{2}$ emissions for the proposed scenarios, the factor used is $3.282 \mathrm{~kg}_{\mathrm{CO} 2 \mathrm{eq}} / \mathrm{kg}_{\text {Diesel fuel }}$ relative to a generic diesel generator for industry purposes [46].

\section{Methodology}

This study is based on the comparison of three scenarios with increasing complexity, describing the energy system in cooperation with the water desalination system. Figure 2 shows the model flowchart for the three proposed scenarios distinguished by different colors: 
1. The Base Case (BC) (black section in Figure 2) models the present situation of the island and comprises the load, a power control and the gen-set. Energy and water supplies completely rely on shipping from the mainland. The power control is based on the power demand, defining the diesel engines' set points.

2. The Renewable energy Configuration $(\mathrm{ReC})$ (green section in Figure 2) provides hints about the effect of the introduction of renewable energy into the small energy grid of the island. This scenario entails the addition of meteorological data and a conversion technology for renewable energy production. The power control is based on the comparison of the power demand with the renewable power availability, defining the diesel engines' set points. Water supply completely depends on the mainland.

3. Desalination/Renewable energy Configuration (DeReC) (blue section in Figure 2), in which a desalination plant is added to the renewable integrated configuration, entailing the addition of the water load, the desalination plant, the water storage tanks and a water control. The power control also takes into account the power request for the water section and the stored water level.

The proposed system models work on a power basis. The developed power control receives information on power demand from the local users $\left(\mathrm{P}_{\mathrm{D}}\right)$, available power from renewable source $\left(\mathrm{P}_{\mathrm{RES}}\right)$, and requested power for the desalination plant $\left(\mathrm{P}_{\mathrm{DES}-\mathrm{R}}\right)$, aiming at the complete replenishment of the water storage. The water control receives information about water load $\left(\mathrm{FR}_{\mathrm{WD}}\right)$ and tanks' state of charge $\left(\mathrm{W}_{\mathrm{SOC}}\right)$, determining the amount of water lacking in storage and the related power request $\left(\mathrm{P}_{\mathrm{DES}-\mathrm{R}}\right)$. Hence, the power control compares the power information and defines the effective power supply to the desalination plant $\left(\mathrm{P}_{\mathrm{DES}}\right)$ and the DEGS power need $\left(\mathrm{P}_{\mathrm{DEGS}}\right)$.

The models proposed in this work were developed and dynamically simulated in TRNSYS (16, Solar Energy Laboratory, University of Wisconsin, Madison, WI, USA) [47]. TRNSYS is a diffused transient analysis software, already adopted in previous works on small islands $[6,41,42,48,49]$. For this work, three components were developed by the authors: The desalination unit and the energy/water controls [50]. The simulations were hourly-based on a year time horizon.

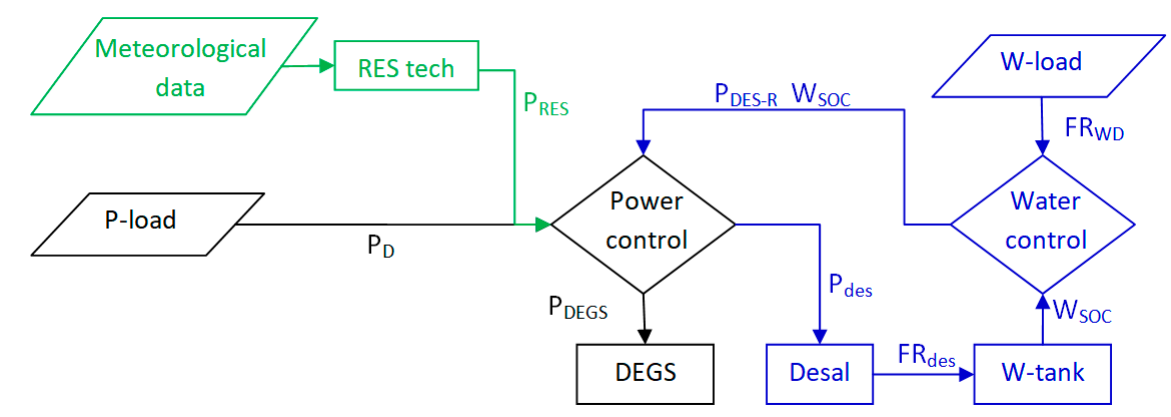

Figure 2. Model flowchart for base case (black section), renewable integrated configuration (green section) and desalination/renewable system (blue section).

\section{Developed Control Logic}

A novel energy/water management algorithm was developed to control the different energy and water flows among the system components. The algorithm defines five operation modes to manage the diesel generators and the desalination set-points with respect to power load of the island, renewable energy availability and water reserve.

First, the control logic guarantees energy and water supply. The aim is production of fresh water, exclusively obtained by the generator set performance improvement, in conjunction with the negative effects of the RES power contribution. In fact, RES contribution will decrease the power request to the DEGS, lowering its performance. The activation of any additional engine only for desalination purposes is limited to the cases in which stored water drops below the fixed minimum level; in all other cases the active engines are exclusively those necessary to cover the island power 
request. The improved DEGS performance is obtained during desalination operations by increasing the engines' duty power, thus their efficiency, by deciding the final power set point $\left(\mathrm{P}_{\mathrm{DEGS}}\right)$ also taking into account a power threshold.

The scheme for the control module is illustrated in Figure 3. The decision process is driven by steps indicated by letters in circles. The five modes' ends are identified by numbered boxes. The set point is given by the comparison of renewable power availability $\left(\mathrm{P}_{\mathrm{RES}}\right)$, reference power set $\left(\mathrm{P}_{\mathrm{REF}}\right)$, end user power demand $\left(\mathrm{P}_{\mathrm{D}}\right)$ and clean water production schedule given by the water storage state of charge $\left(\mathrm{W}_{\mathrm{SOC}}\right)$ that is intended to be maintained between a minimum $\left(\mathrm{W}_{\mathrm{m}}\right)$ and a maximum $\left(\mathrm{W}_{\mathrm{M}}\right)$ value.

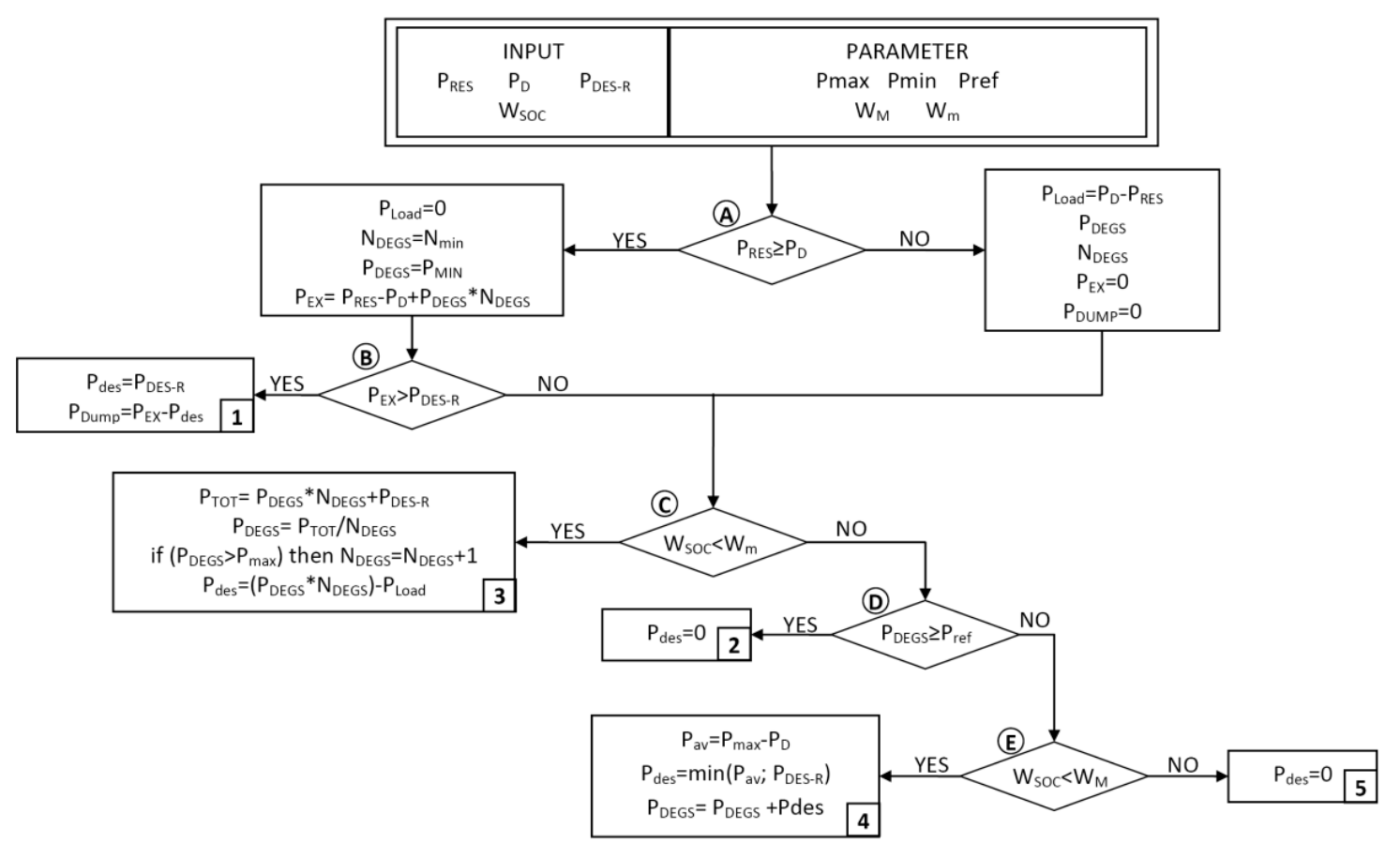

Figure 3. Energy/water control logic scheme.

The first step checks for renewable power surplus. If renewable power $\left(\mathrm{P}_{\mathrm{RES}}\right)$ exceeds the power demand $\left(\mathrm{P}_{\mathrm{D}}\right)$, the DEGS is operated at minimum duty; else, an initial power set point and the engine's number will be determined by means of the standard TRNSYS generator set control [47], accounting for engine min-max power ratio. Hence, in case of renewable power higher than power demand, the renewable power excess added with the power from DEGS on minimum duty, resulting in $P_{E X}$, will be directly used for desalination purposes if $P_{E X}$ is higher than the maximum power request for desalination $\left(\mathrm{P}_{\mathrm{DES}-\mathrm{R}}\right)$ (mode 1$)$.

If $\mathrm{P}_{\mathrm{EX}}$ is less than $\mathrm{P}_{\mathrm{DES}-\mathrm{R}}$ or $\mathrm{P}_{\mathrm{RES}}$ is less than $\mathrm{P}_{\mathrm{D}}$, a new generator set point is determined having two options:

1. Power (and eventually number) of on-duty engines changes to meet the desalination plant power request, when the water tank state of charge is below $W_{m}$ (mode 3); and,

2. On-duty engine power increases when state of charge is between $W_{m}$ and $W_{M}$ (mode 4).

If DEGS already works at a satisfactory duty point higher than $\mathrm{P}_{\mathrm{REF}}$, there will be no changes in the DEGS set points and no desalination (mode 2).

Desalination is also cut-out when water tanks are full (mode 5).

It is worth noting how the $W_{M}$ value affects the control behavior: If $W_{M}=0$, then engines are never switched on only for water desalination purposes; if $W_{M}$ is between 0 and 1 , then in some cases 
engines may be switched on only for desalination purposes; and, if $W_{M}=1$ then engines are always allowed to be switched on for desalination purposes.

Regarding the ReC scenario, due to the absence of desalination, the control logic operation is limited to modes 1, 2 and 5. Thus no gen-set power adjustments or increase in engine numbers will take place. In particular, in case of RES power exceeding the load, the renewable power excess added with the power from DEGS on minimum duty will be completely dumped (mode 1). In case of power load higher than RES availability, the direction on mode 2 or mode 5 only indicates whether the engines are working above the reference power or not.

\section{Results and Discussion}

The global performance of the simulated scenario is shown in Table 3. In view of the island's user load (i.e., 10,663.68 MWh/year), the RES availability considered in this work amounts to $3147 \mathrm{MWh}$ /year, which represents a potential load coverage of $30 \%$.

Table 3. Overall performance comparison.

\begin{tabular}{cccc}
\hline Performance Index & \multicolumn{3}{c}{ Scenario } \\
\cline { 2 - 4 } & BC & ReC & DeReC \\
\hline RES energy availability (MWh/year) & - & 3146.64 & 3146.64 \\
Engines energy output (MWh/year) & $10,664.68$ & 8125.65 & 9256.32 \\
Dumped energy (MWh/year) & - & 536.61 & 229.42 \\
Overall engines duty time (h/year) & 12,167 & 11,097 & 11,390 \\
Mean engines power $(\mathrm{kW})$ & 876.44 & 732.24 & 812.67 \\
Fuel consumption $\left(10^{3} \mathrm{~L}\right)$ & 2778.26 & 2178.49 & 2439.50 \\
Engines mean electric efficiency & 0.3874 & 0.3691 & 0.3784 \\
Fuel specific consumption $(\mathrm{L} / \mathrm{kWh})$ & 0.2605 & 0.2681 & 0.2635 \\
Energy to desalination $(\mathrm{MWh} /$ year $)$ & - & - & 1507.94 \\
DEGS-related carbon dioxide emissions (t $\mathrm{t}_{\mathrm{CO} 2 \mathrm{eq}} /$ year $)$ & 7705.21 & 6041.81 & 6765.69 \\
\hline
\end{tabular}

Due to demand/RES hourly mismatch, a RES surplus of 275.66 MWh/year is found in the ReC, indicating the effective RES load coverage amounts to $25 \%$. Moreover, based on the hypothesis of having one engine always on duty, the global dumped energy rises to $536.61 \mathrm{MWh} /$ year. Nevertheless, the RES introduction allows a reduction of the overall engines' duty time from 12,167 to 11,097 h/year, with a $24 \%$ reduction of the global engines' energy output and a $22 \%$ fuel consumption decrease. The effect is a $22 \%$ reduction of the equivalent carbon dioxide emissions. Besides these positive effects, a $16.45 \%$ decrease of the average engine's power is computed, affecting the efficiency that passes from 0.3874 to 0.3691 . The control logic use results are presented in Table 4 and Figure 4 . As the ReC scenario is in absence of the desalination system, the engines' power modulation is never engaged; consequently, there is no use of modes 3 and 4. Most of the time (i.e., $6160 \mathrm{~h} /$ year), the DEGS works with engine power higher than the reference power (mode 2). This behavior is distributed throughout the simulated year period. For $1667 \mathrm{~h} /$ year, the engines work at a power set point lower than the reference power (mode 5), but the absence of desalination does not allow power to rise to the power set point. This mode of behavior is also distributed throughout the year, but, as expected, it shows some holes in April and August when the higher power request better dampens the RES fluctuations. Finally, during $933 \mathrm{~h} /$ year, renewable energy availability exceeds the user load, resulting in the DEGS working with only one active engine at its minimum power, and the excess RES and DEGS power entirely dumped (mode 1). In this case, the mode distribution over the year clearly shows numerous holes, with a particular long amplitude during July and August, when the tourist-related power load far exceeds the RES contribution.

When analyzing the desalination/renewable configuration, the surplus power is used to feed the desalination plant. In particular, $276 \mathrm{MWh}$ /year of the RES energy remains available for desalination after load coverage. Of such energy, $208 \mathrm{MWh}$ /year are used to match the desalination side power 
request, allowing $58 \times 10^{3} \mathrm{~m}^{3} /$ year water production (i.e., $13.8 \%$ of the entire water load). In the DeReC scenario, the dumped energy, distributed over $791 \mathrm{~h}$, is reduced with respect to the $\mathrm{ReC}$ scenario and amounts to about $230 \mathrm{MWh}$ /year. Ninety-eight percent of the power dump is due to an excess of power availability with respect to the desalination side power request. The remaining $2 \%$ of the dumped energy is attributable to the water storage fullness. As the number of engines is allowed to increase in case of water shortage, the number of overall engines' duty time is slightly higher than in the ReC. A $10.98 \%$ increase of the mean engines' power is registered with respect to $\mathrm{ReC}$, even though it represents only $97.72 \%$ of the mean engines' power in the BC, negatively affecting fuel consumption and engine efficiency. Carbon dioxide emissions are approximately $12 \%$ higher than in $\operatorname{ReC}$ but $12 \%$ less than in BC.

Table 4. Occurrence of control logic modes.

\begin{tabular}{cccccc}
\hline \multirow{2}{*}{ Scenario } & \multicolumn{5}{c}{ Mode Occurrence (h) } \\
\cline { 2 - 6 } & $\mathbf{1}$ & $\mathbf{2}$ & $\mathbf{3}$ & $\mathbf{4}$ & $\mathbf{5}$ \\
\hline $\operatorname{ReC}$ & 933 & 6160 & 0 & 0 & 1667 \\
$\mathrm{DeReC}$ & 791 & 4453 & 2229 & 1287 & 0 \\
\hline
\end{tabular}

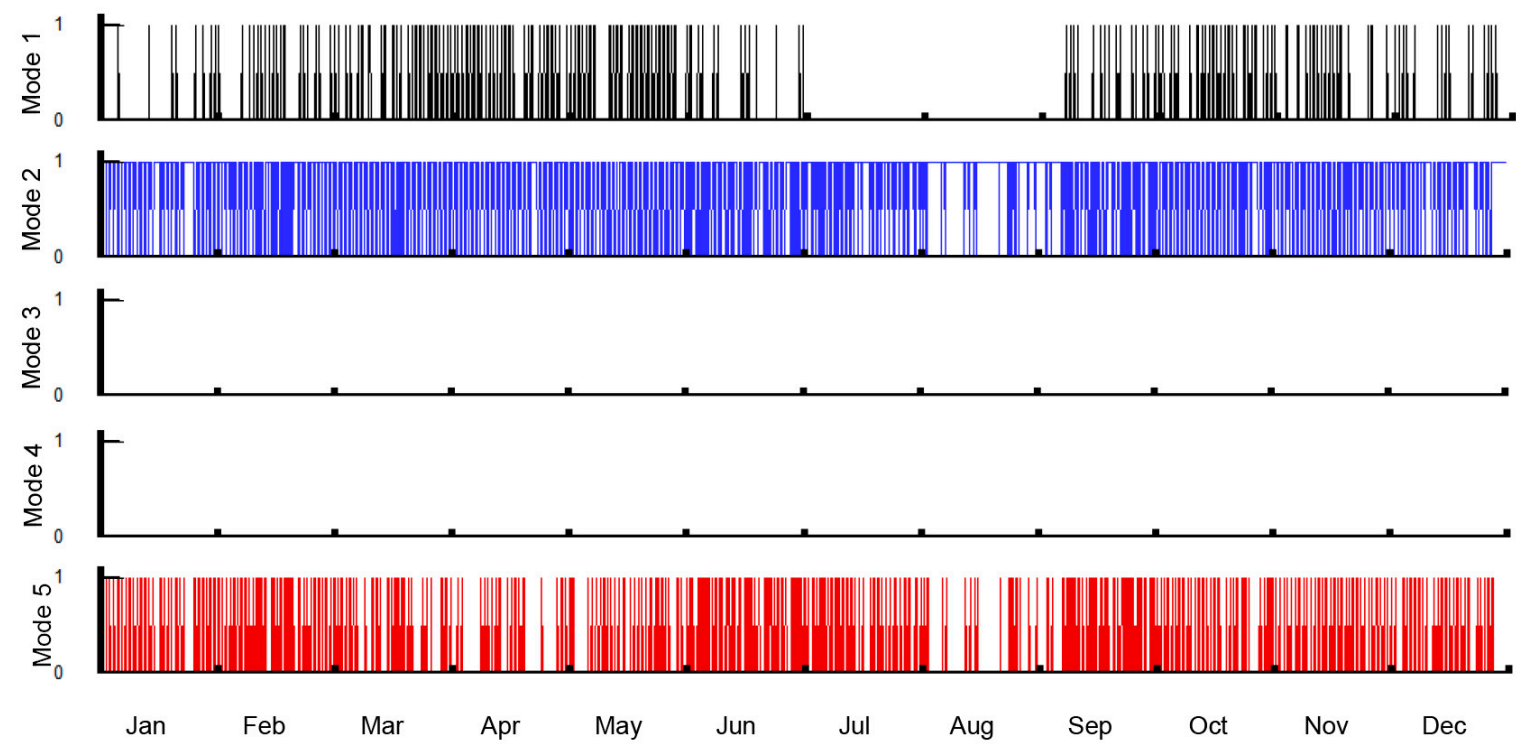

Figure 4. Operating modes occurrence of the $\mathrm{ReC}$ system during a reference year

Table 4 and Figure 5 show the results for the operating modes deriving from the control logic application. In the DeReC scenario, the water storage fullness is never concurrent with the possibility to increase the engines' power set point, hence mode 5 is never engaged. It is evident that mode 2 remains the most frequent situation distributed over the year, with an occurrence of $4453 \mathrm{~h}$ and a gap during August. For 2229 h, the system registers a water level less than the fixed minimum (mode 3), conducing to the increase of the active engines' power independently from the engines' power set point related to the island power load coverage. Moreover, for $322 \mathrm{~h}$ an additional engine is switched on in order to re-establish, at least, the fixed minimum water store. In Figure 5 it can be noticed that mode 3 is the only operation mode active during August, which is the most critical period of the year for water supply in the island. An increase of the initial engines' power set points for desalination purposes is also registered for $1287 \mathrm{~h}$ in mode 4 , as the engines' power is less than the reference power. 


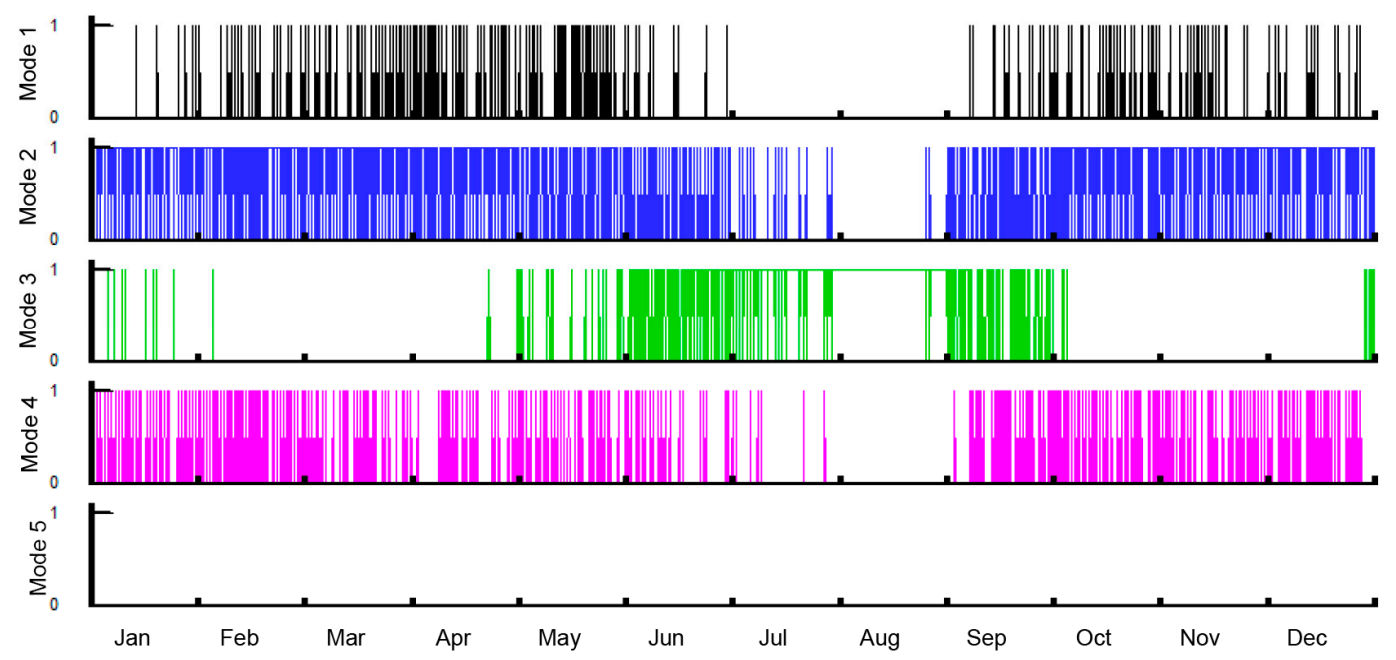

Figure 5. Operating modes of the DeReC system during a reference year.

As expected, the PV-based RES power availability, distributed throughout the year, makes a higher contribution during the summer period, matching with the higher user power demand (Figure 6a). In the summer period, the RES availability never exceeds the load, while during the rest of the year RES surplus reaches peaks of about $800 \mathrm{~kW}$, with yearly RES energy surplus of about $276 \mathrm{MWh} /$ year distributed over $933 \mathrm{~h}$. Nevertheless, due to the hypothesis of a constantly active engine, in the ReC the dumped energy increases to a value of $537 \mathrm{MWh} /$ year, while the energy absorption of the desalination side allows a decrease of the dumped energy to the value of $229 \mathrm{MWh} /$ year in the DeReC. Figure $6 \mathrm{~b}$ shows the hourly dumped power curves for the ReC and DeReC. One can observe the similar distribution of the two curves with lower peaks for the DeReC, and the absence of power dumps from 1 July to 5 September.
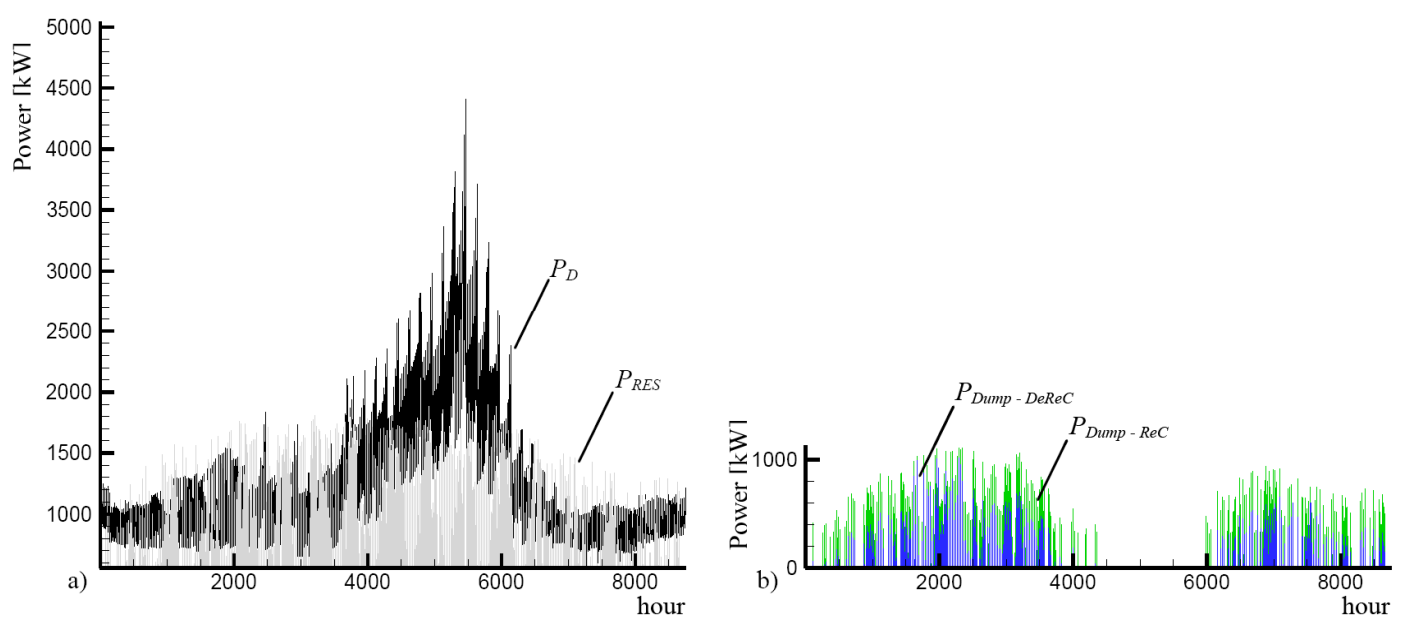

Figure 6. Hourly based curves for (a) user load $\left(\mathrm{P}_{\mathrm{D}}\right.$, black line) and renewable power availability $\left(\mathrm{P}_{\mathrm{RES}}\right.$, grey line) during a reference year and $(\mathbf{b})$ dumped power in the $\mathrm{ReC}\left(\mathrm{P}_{\text {Dump-ReC }}\right.$, green line $)$ and DeReC $\left(P_{\text {Dump-DeReC }}\right.$, blue line), during a reference year.

Referring to the DeReC, energy supplied to the desalination plant globally amounts to about 1.5 GWh, with values exceeding 240 MWh in July and August (entailing 33\% of the whole supply), and values below $100 \mathrm{MWh}$ from January to April and from October to December (Table 5). The desalination plant works $4283 \mathrm{~h}$ /year. The overall desalination plant duty time amounts to $32,930 \mathrm{~h} /$ year. 
Table 5. Monthly distribution of the energy sent to the desalination plant.

\begin{tabular}{ccccccccccccccc}
\hline \multicolumn{2}{c}{ Month } & $\mathbf{1}$ & $\mathbf{2}$ & $\mathbf{3}$ & $\mathbf{4}$ & $\mathbf{5}$ & $\mathbf{6}$ & $\mathbf{7}$ & $\mathbf{8}$ & $\mathbf{9}$ & $\mathbf{1 0}$ & $\mathbf{1 1}$ & $\mathbf{1 2}$ & Total \\
\hline $\mathrm{E}_{\mathrm{DES}}$ & $(\mathrm{MWh})$ & 71.17 & 68.43 & 76.83 & 93.99 & 132.27 & 186.19 & 240.11 & 263.11 & 151.68 & 89.73 & 69.73 & 64.7 & 1507.94 \\
\hline
\end{tabular}

Figure 7 shows the occurrence distribution of the contemporarily active $\mathrm{RO}$ units during the year. Most of the time (i.e., $3463 \mathrm{~h} /$ year), each of the eight $\mathrm{RO}$ units is working. The number of hours in which only seven $\mathrm{RO}$ units are simultaneously on duty is $636 \mathrm{~h} /$ year. In these two cases, the operations are distributed throughout the year. A different behavior is shown for six to only one active RO units. In these cases, it can be seen that such situations are infrequent with an occurrence ranging from 11 to $45 \mathrm{~h}$, passing from one single unit to six simultaneously active units. Moreover, these cases are focused on two periods of the year, corresponding to high storage fill levels which temporary reduce the need to desalinate water.

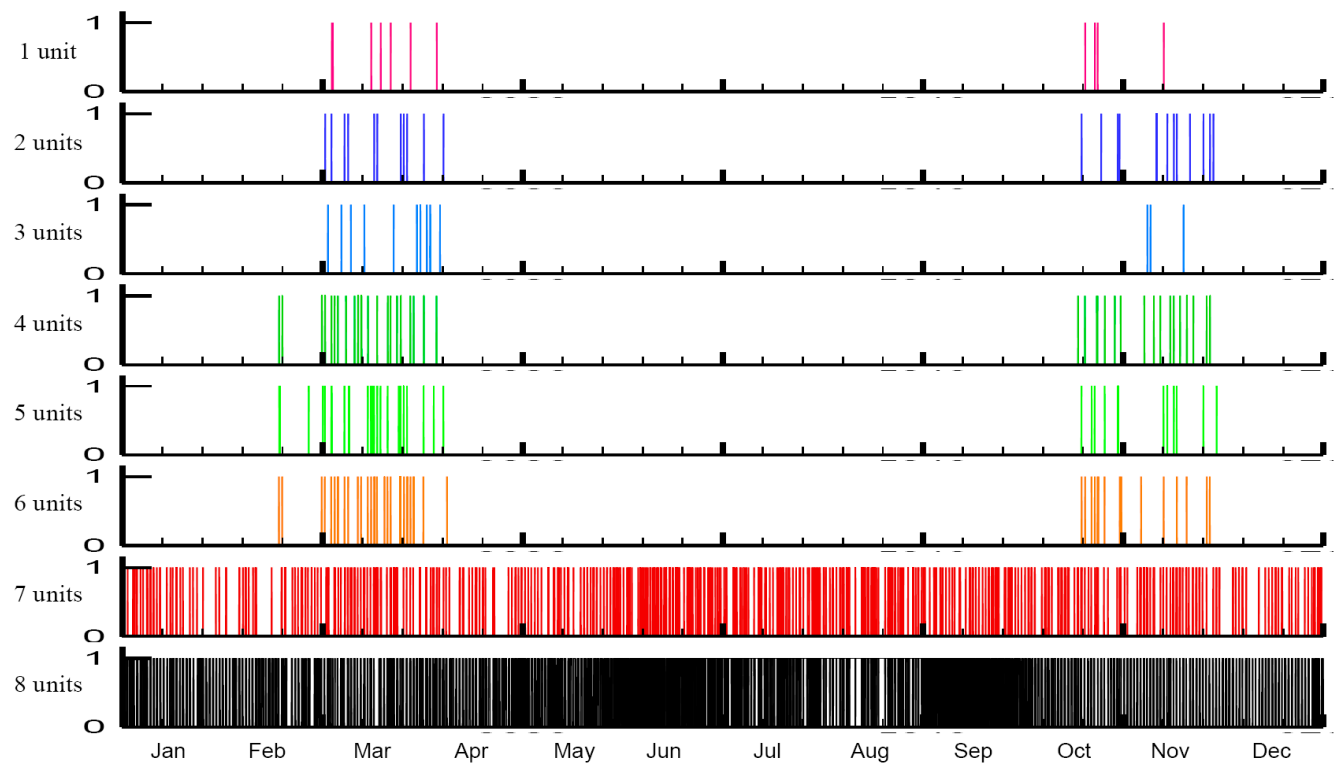

Figure 7. Occurrence distribution of number of active RO units in the DeReC system during a reference year.

The DeReC scenario is able to produce $412 \times 10^{3} \mathrm{~m}^{3} /$ year of fresh water (i.e., $98 \%$ of the total water load), with the $2 \%$ deficit concentrated in the summer period. Figure 8 shows the water content in storage. The maximum water content is in correspondence with the high renewable power availability and the low users' power and water loads in the periods from 2 March-10 April and 15 October-3 November. It is worth noting that the power dump is concentrated in the same period (see Figure 6b) indicating that the dump is strictly related to the fullness of the water storage. For the remaining part of the year, the water content remains at levels higher than the fixed minimum of $600 \mathrm{~m}^{3}$, with the exception of the summer period, in which water deficits are also registered with a total water lack of $4312 \mathrm{~m}^{3}$ /year occurring for $147 \mathrm{~h}$ distributed between 18 July and 29 August. In these cases, the DEGS are managed by increasing the duty power or by increasing the number of active engines, and the desalination station works at its maximum with very few exceptions (i.e., $26 \mathrm{~h}$ in which the active RO units number seven). This indicates that the water demand is higher than the RO station's capability to completely cover the water request. Two solutions may be taken into account: (a) Resorting to an additional small size RO unit for water peak shaving purposes or, (b) substituting some of the RO units with increased water production (and power absorption) ones.

To give hints about the load-levelling performance of the system, the behavior of the supplied power from the DEGS in the three proposed scenarios is shown in Figure 9 for three representative days: 
(a) A winter day (Saturday, 4 February); (b) a spring day (Thursday, 10 May); and, (c) a summer day (Thursday, 16 August). Additionally, Table 6 shows the DEGS supplied power maximum imbalance data of the $\operatorname{ReC}$ and DeReC curves with respect to the $\mathrm{BC}$ curves in the selected winter, spring and summer days. In Figure 9, the black line, corresponding to the BC, indicates the final users' load curve, also for the other simulated scenarios. Generally, the intermediate position of the DeReC curve (blue line), with respect to the $\mathrm{BC}$ and $\mathrm{ReC}$ curves, demonstrates the ability of the desalination plant to act as a remedy to the DEGS power drops due to resorting to renewable energy sources. It is also worth highlighting that the RES fluctuations are barely predictable $(\mathrm{ReC})$, while the proposed DeREC allows a more controlled operation of DEGS with power fluctuations that rely mostly on the adopted control logic limits.

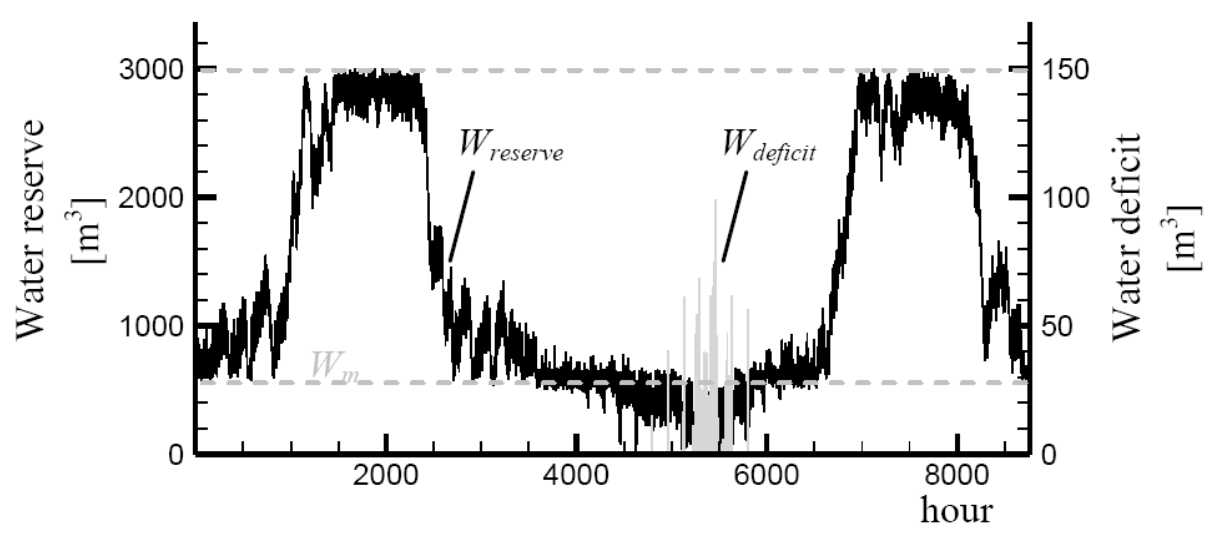

Figure 8. Hourly based curves for water reserve (left axis, black line) and water supply deficit (right axis, grey line) in DeReC during a reference year.
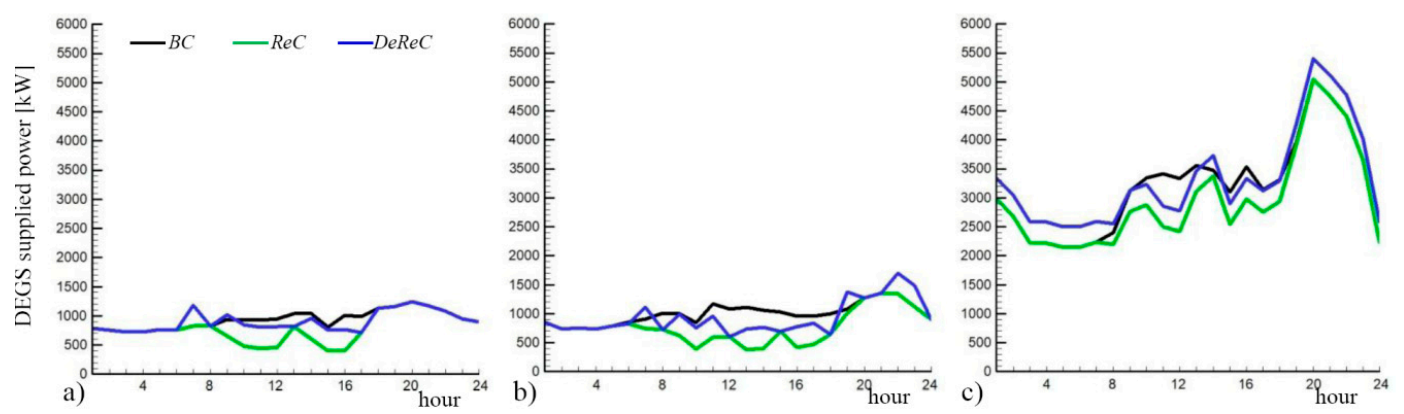

Figure 9. Hourly based curves for DEGS supplied power in BC (black line), ReC (green line) and DeReC (blue line) for three specific days: (a) 4 February, (b) 10 May (c) 16 August.

Table 6. DEGS supplied power maximum imbalance data for $\mathrm{ReC}$ and $\mathrm{DeReC}$ with respect to BC in three specific days.

\begin{tabular}{ccccccc}
\hline \multirow{2}{*}{ Day } & \multicolumn{2}{c}{ Daily Energy Difference } & \multicolumn{3}{c}{ Maximum Power Imbalance } \\
\cline { 2 - 7 } & ReC vs. BC & DeReC vs. BC & ReC vs. BC & \multicolumn{2}{c}{ DeReC vs. BC } \\
\cline { 2 - 7 } & MWh & MWh & kW & \% & kW & \% \\
\hline Winter day-4 February & -3.65 & -0.77 & 605.10 & 60.0 & 359.44 & 43.5 \\
Spring day-10 May & -5.50 & -1.55 & 727.49 & 65.6 & 468.88 & 43.5 \\
Summer day-16 August & -5.21 & 3.42 & 911.02 & 26.7 & 551.58 & 16.8 \\
\hline
\end{tabular}

For the winter day (Figure 9a), the RES availability in the ReC entails a DEGS power decrease in the central hours of the day from 8 a.m. to 5 p.m., with a maximum imbalance of $60 \%$, corresponding to 
$605 \mathrm{~kW}$, with respect to the BC curve. The DeReC shows more constant behavior, with a maximum imbalance of $360 \mathrm{~kW}$, corresponding to $43.5 \%$, with respect to BC. Moreover, the two cases in which the DEGS power supply exceeds the $\mathrm{BC}$ are caused by the maximum power request from the desalination plant side due to storage water shortage. Concerning the spring day (Figure 9b), as the RES supply increases in power and time, the gap between the $\mathrm{ReC}$ and $\mathrm{BC}$ curves show a maximum difference increase to $66 \%$, which corresponds to $727 \mathrm{~kW}$. In this case, the DeReC also presents intermediate values with a more linear behavior, with a maximum gap of $43.5 \%$, corresponding to $467 \mathrm{~kW}$. The summer day (Figure 9c), represents the most extreme working conditions of the plant due to the high final users' power request. The ReC and DeReC curves fluctuate more than in the other days and the DeReC curve traces the ReC curve with a constant $395 \mathrm{~kW}$ shift, which is the power contribution for the desalination plant. A maximum power imbalance of $911 \mathrm{~kW}$ is registered; nevertheless, as higher power values are involved in this period, the corresponding percentage decreases to $26.7 \%$. In the DeReC, the DEGS power output exceeds the BC curve for most of the day-time as the desalination power request at its maximum rate (aimed at replenishing the almost-empty water storage) is added to the original users' power load (BC curve). An exception is the 7 h-period from 10 a.m. to 5 p.m., in which the RES contribution allows the DeReC curve to under-shoot the BC curve.

Looking at the daily DEGS supplied energy difference between ReC and DeReC with respect to $\mathrm{BC}$ in the three selected days (Table 6), it can be noticed, by the negative values, that in most cases the $\mathrm{ReC}$ and DeReC scenarios show lower DEGS energy requests than BC. The exception is represented by the DeReC scenario during the summer day, as the continuous desalination energy request is well above the RES contribution.

Figure 10 shows the hourly distribution of the engine efficiency for the proposed scenarios. It is evident from the comparison of Figure 10a,b that the introduction of the renewable technology in the local power system worsens the DEGS performance, corresponding to a more dispersed efficiency values distribution, passing from a $0.3585-0.4095$ range to a $0.2963-0.4095$ range with an average efficiency of 0.3874 and 0.3691 in the $\mathrm{BC}$ and $\mathrm{ReC}$, respectively. On the other hand, the use of the desalination plant (Figure 10c), while having an efficiency range similar to the $\mathrm{ReC}$, features a denser distribution of high efficiency operations driving the average value to 0.3784 . Notably, both $\operatorname{ReC}$ and DeReC feature an elevation of minimum efficiency in summer hours (Figure 10b,c) above 0.35, as a consequence of the engines working closer to their maximum power rating. In this respect, the $\mathrm{DeReC}$ scenario also exhibits the positive effects of the water-energy nexus, with a remarkably extended time interval of higher average engine efficiencies, indicating, once more, the impact of the proposed solution to the RES balancing problems in small off-grid power systems.
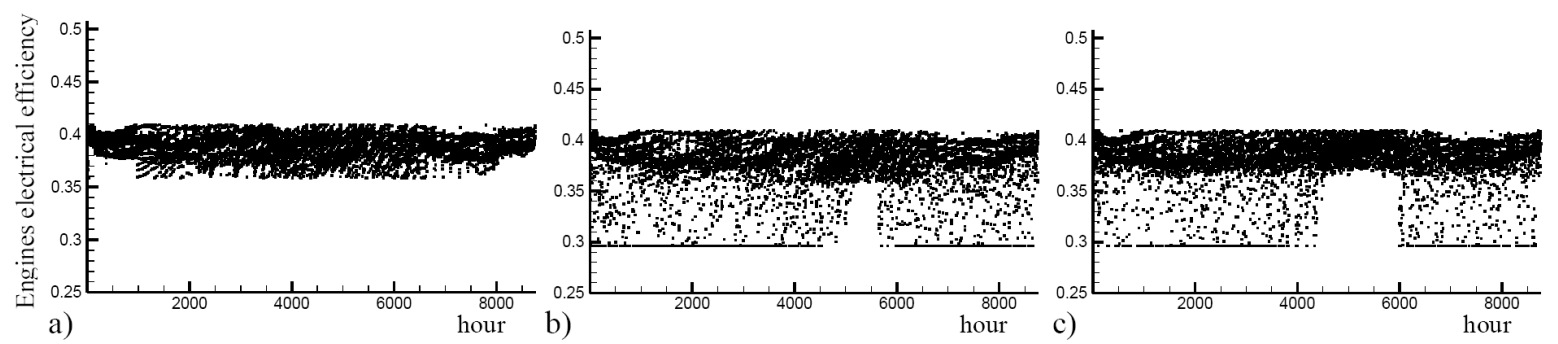

Figure 10. Hourly based electrical efficiency of the engines for a reference year in (a) BC, (b) $\operatorname{ReC}$, and (c) DeReC.

The last considered factor is the equivalent carbon dioxide emissions, shown in Figure 11. In BC and $\mathrm{ReC}$, the emissions related to the shipped water supply to the island are also taken into account, as evaluated in [43]. The $\mathrm{CO}_{2 \mathrm{eq}}$ emissions for the fuel transport are not taken into account, as there is not dedicated transportation. Indeed, fuel procurement is made by means of the same ferry-boats that transport both people and goods to the island. The higher environmental sustainability of the DeReC is demonstrated, despite its partial reliance on fuel-derived energy. The BC and ReC 
curves are considerably higher than the DeReC curve, with a yearly emissions impact of $+30 \%$ and $+54 \%$ for $\mathrm{ReC}$ and BC, respectively. The emissions reduction is most marked in the May-September period, with monthly emissions savings of over $200 \mathrm{t}_{\mathrm{CO} 2 \mathrm{eq}}$ for the DeReC with respect to $\mathrm{BC}$ and $\mathrm{ReC}$. Globally, the emissions in the BC, $\operatorname{ReC}$ and DeReC amount to $10,434 \mathrm{t}_{\mathrm{CO} 2 \mathrm{eq}}, 8771 \mathrm{t}_{\mathrm{CO}}$ eq and $6766 \mathrm{t}_{\mathrm{CO}}$ eq, respectively, indicating that the proposed DeReC system allows emissions savings of about $65 \%$ with respect to the $\mathrm{BC}$ and $\mathrm{ReC}$.

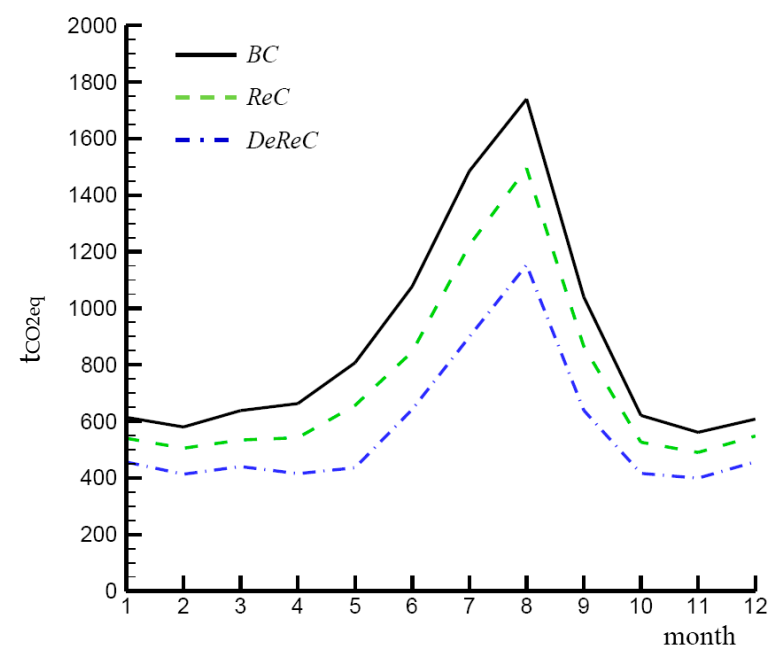

Figure 11. Monthly based curves for equivalent carbon dioxide emissions in BC (solid black line) ReC (dashed green line) and DeReC (dashed-dotted blue line), accounting for water shipping emissions in BC and ReC.

\section{Conclusions}

The present study proposes a novel management scheme for integrated energy/water systems in remote areas. The control logic aims at a desalination activity no longer subjected to energy availability or water production goals but intended to smooth the load curve modified by RES fluctuations. Indeed, in the proposed scheme, water production exclusively depends on the need to balance RES fluctuations on the load curve in order to mitigate the negative effects of RES on the DEGS performance. Thus, desalination operations are only fed by energy derived from RES surplus and from set point adjustment of the already active diesel-engines. The activation of additional engines for desalination purposes is allowed only in case of water level emergency situations. These working conditions were implemented in the developed control logic of the integrated energy/water system.

The comparison of the obtained results demonstrates the capability of the proposed system management to smooth the load gaps resulting from RES fluctuations, with the desalination systems acting as an additional load during the summer period and as a one-way energy storage during the rest of the year.

The analysis demonstrated the positive effects of the proposed DeReC system on the local power system. On the RES side, the presence of the desalination system ensures higher renewable energy absorption; the RES energy dump recovery was over $50 \%$ with respect to the renewable energy integrated system without desalination. On the diesel engines side, the $\mathrm{DeReC}$ allows a $9 \%$ recovery of the mean engines' power with respect to the $16.45 \%$ drop related to RES introduction in the ReC. Moreover, a recovery of $2.4 \%$ of the mean engines' electric efficiency is registered after a $4.7 \%$ drop related to the RES introduction with respect to the base case scenario. From the global emissions point of view, taking into account current water shipping emissions, the proposed energy/water system entails equivalent $\mathrm{CO}_{2}$ emissions reduction of approximately $50 \%$ with respect to the current island situation and $30 \%$ with respect to the proposed renewable energy integration scenario. 
Beside the relevance of the illustrated results, the proposed system has the capability to cover a $98 \%$ share of water demand (easily scalable to $100 \%$ with a few small control logic adjustments), mainly by adjusting the power set-point of the diesel gen-set.

It is easy to conceive of similar stand-alone power systems with water shortage problems and the uncontrolled presence of distributed renewable energy. The present study demonstrates that the addition of a relevant desalination power load to a small off-grid energy system may not represent a negative complex addition to the system, but may be able to smooth the DEGS management problems that usually occur with the inevitable RES penetration on such systems. Furthermore, it demonstrates the possibility to get benefits on the emissions side while obtaining a necessity such as fresh water. This implies the possibility of going beyond RES penetration limitations on islands or remote off-grid areas by creating a water/energy nexus.

Author Contributions: Conceptualization, E.T.; Formal analysis, A.C. and E.T.; Investigation, E.T.; Methodology, A.C. and E.T.; Supervision, A.C.; Validation, A.C. and E.T.; Visualization, E.T.; Writing - original draft, A.C. and E.T.

Acknowledgments: The Authors express their gratitude to E. Cima (Acqua Latina Spa) for the fruitful discussion and the documentations provided.

Conflicts of Interest: The authors declare no conflict of interest

\section{Nomenclature}

BC Base case Configuration

DEGS Diesel Engine Generator Set

DeReC Desalination/Renewable energy Configuration

$\mathrm{FR}_{\text {des }} \quad$ water production index

$\mathrm{FR}_{\mathrm{WD}} \quad$ water load index

$\mathrm{N}_{\text {DEGS }}$ number of active diesel engines

Nmin minimum number of active diesel engines

$\mathrm{P}_{\mathrm{D}} \quad$ local users power demand

$P_{\text {DEGS }} \quad$ DEGS power

$P_{\text {DES }} \quad$ effective power supply to desalination

$P_{\text {DES-R }} \quad$ desalination plant power request

$P_{\text {DUMP }} \quad$ power curtailment

$P_{\text {EX }} \quad$ power excess

$\mathrm{P}_{\text {LOAD }} \quad$ power demand after RES deduction

$\mathrm{P}_{\max } \quad$ Engine maximum power

$\mathrm{P}_{\min } \quad$ Engine minimum power

$P_{\text {ref }} \quad$ Engine reference power

RO Reverse Osmosis

$P_{\text {RES }} \quad$ RES power availability

PV Photovoltaic

$\mathrm{ReC} \quad$ Renewable energy Configuration

RES Renewable Energy Source

$\mathrm{W}_{\mathrm{m}} \quad$ Lower limit for $\mathrm{W}_{\mathrm{SOC}}$

$\mathrm{W}_{\mathrm{M}} \quad$ Upper limit for $\mathrm{W}_{\mathrm{SOC}}$

$\mathrm{W}_{\mathrm{SOC}} \quad$ water storage state of charge

\section{References}

1. Blechinger, P.; Seguin, R.; Cader, C.; Bertheau, P.; Breyer, C. Assessment of the global potential for renewable energy storage systems on small islands. Energy Procedia 2014, 46, 294-300. [CrossRef]

2. Public Power Corporation (PPC). Annual Production Plan of Autonomous Power Stations. Technical Report Prepared by Island Production Department of Greek Public Power Corporation, Athens, Greece. 2015. Available online: https:/ /www.dei.gr/documents/ (accessed on 18 December 2017). 
3. Kaldellis, J.K.; Kondili, E.M. The water shortage problem in the Aegean archipelago islands: Cost-effective desalination prospects. Desalination 2007, 216, 123-138. [CrossRef]

4. Cima, E. (Acqualatina S.P.A., Italy). Personal Communication, 2016.

5. Corsini, A.; Rispoli, F.; Gamberale, M.; Tortora, E. Assessment of h2- and h2o-based renewable energy-buffering systems in minor islands. Renew. Energy 2009, 34, 279-288. [CrossRef]

6. Beccali, M.; Bonomolo, M.; Di Pietra, B.; Ippolito, M.G.; La Cascia, D.; Leone, G.; Lo Brano, V.; Monteleone, F.; Zizzo, G. Characterization of a small Mediterranean island end-users' electricity consumption: The Case of Lampedusa. Sustain. Cities Soc. 2017, 35, 1-12. [CrossRef]

7. Lin, J.-H.; Wu, Y.-K.; Lin, H.-J. Successful experience of renewable energy development in several offshore islands. Energy Procedia 2016, 100, 8-13. [CrossRef]

8. Meschede, H.; Holzapfel, P.; Kadelbach, F.; Hesselbach, J. Classification of global island regarding the opportunity of using RES. App. Energy 2016, 175, 251-258. [CrossRef]

9. Blechinger, P.; Cader, C.; Bertheau, P.; Huyskens, H.; Seguin, R.; Breyer, C. Global analysis of the techno-economic potential of renewable energy hybrid systems on small islands. Energy Policy 2016, 98, 674-687. [CrossRef]

10. Gils, H.C.; Simon, S. Carbon neutral archipelago-100\% renewable energy supply for the Canary Islands. Appl. Energy 2017, 188, 342-355. [CrossRef]

11. Maïzi, N.; Mazauric, V.; Assoumou, E.; Bouckaert, S.; Krakowski, V.; Li, X.; Wang, P. Maximizing intermittency in 100\% renewable and reliable power systems: A holistic approach applied to Reunion Island in 2030. Appl. Energy 2017. [CrossRef]

12. Kuang, Y.; Zhang, Y.; Zhou, B.; Li, C.; Cao, Y.; Li, L.; Zeng, L. A review of renewable energy utilization in islands. Renew. Sustain. Energy Rev. 2016, 59, 504-513. [CrossRef]

13. Irena, Grein-Global Renewable Energy Islands Network, Supporting Island Transitions to a Renewable Energy Future. Available online: http:/ / www.irena.org/ (accessed on 18 December 2017).

14. Rocky Mountain Institute and Carbon War Room, the Ten Island Renewable Challenge. Available online: http:/ / carbonwarroom.com/content/islands-energy-program (accessed on 18 December 2017).

15. Bottini, A. Sulla briologia delle isole italiane. Webbia 1907, 2, 345-402. [CrossRef]

16. Eurelectric, EU Islands: Towards a Sustainable Energy Future, D./2012/12.105/24. June 2012. Available online: https: / /cdn.eurelectric.org/media/1724/ (accessed on 18 December 2017).

17. Sigrist, L.; Lobato, E.; Rouco, L.; Gazzino, M.; Cantu, M. Economic assessment of smart grid initiatives for island power systems. Appl. Energy 2017, 189, 403-415. [CrossRef]

18. Tzanes, G.T.; Zafirakis, D.; Papapostolou, C.; Kavadias, K.; Kaldellis, J.K. PHAROS: An Integrated Planning Tool for Meeting the Energy and Water Needs of Remote Islands using RES-based Hybrid Solutions. Energy Procedia 2017, 142, 2586-2591. [CrossRef]

19. Kaldellis, J.K.; Zafirakis, D.; Kavadias, K. Techno-economic comparison of energy storage systems for island autonomous electrical networks. Renew. Sustain. Energy Rev. 2009, 13, 378-392. [CrossRef]

20. Gori, F.; Ludovisi, D.; Cerritelli, P.F. Forecast of oil price and consumption in the short term under three scenarios: Parabolic, linear and chaotic behaviour. Energy 2007, 32, 1291-1296. [CrossRef]

21. Dai, J.; Wu, S.; Han, G.; Weinberg, J.; Xie, X.; Wu, X.; Song, X.; Jia, B.; Xue, W.; Yang, Q. Water-energy nexus: A review of methods and tools for macro-assessment. Appl. Energy 2017, 210, 393-408. [CrossRef]

22. Alkaisi, A.; Mossad, R.; Sharifian-Barforoush, A. A Review of the Water Desalination Systems Integrated with Renewable Energy. Energy Procedia 2017, 110, 268-274. [CrossRef]

23. Goosen, M.F.A.; Mahmoudi, H.; Ghaffour, N. Today's and Future Challenges in Applications of Renewable Energy Technologies for Desalination. Crit. Rev. Environ. Sci. Technol. 2014, 44, 929-999. [CrossRef]

24. Gude, V.G.; Nirmalakhandan, N.; Deng, S. Renewable and sustainable approaches for desalination. Renew. Sustain. Energy Rev. 2010, 14, 2641-2654. [CrossRef]

25. Segurado, R.; Costa, M.; Duić, N.; Carvalho, M.G. Integrated analysis of energy and water supply in islands. Case study of S. Vicente, Cape Verde. Energy 2015, 92, 639-648. [CrossRef]

26. Liu, J.; Mei, C.; Wang, H.; Shao, W.; Xiang, C. Powering an island system by renewable energy-A feasibility analysis in the Maldives. Appl. Energy 2017. [CrossRef]

27. Abdelkareem, M.A.; Assad, M.E.H.; Sayed, E.T.; Soudan, B. Recent progress in the use of renewable energy sources to power water desalination plants. Desalination 2018, 435, 97-113. [CrossRef] 
28. Mentis, D.; Karalis, G.; Zervos, A.; Howells, M.; Taliotis, C.; Bazilian, M.; Rogner, H. Desalination using renewable energy sources on the arid islands of south aegean sea. Energy 2016, 94, 262-272. [CrossRef]

29. Al-Nory, M.; El-Beltagy, M. An energy management approach for renewable energy integration with power generation and water desalination. Renew. Energy 2014, 72, 377-385. [CrossRef]

30. Gónzalez, A.; Delgado, L.; Avia, F.; Mateos, J. Wind and photovoltaic powered reverse osmosis seawater desalination plant. In Seventh E.C. Photovoltaic Solar Energy Conference; Springer: Dordrecht, The Netherlands, 1987; pp. 240-244. [CrossRef]

31. Khalifa, A.J.N. Evaluation of different hybrid power scenarios to reverse osmosis, (ro) desalination units in isolated areas in Iraq. Energy Sustain. Dev. 2011, 15, 49-54. [CrossRef]

32. Goldemberg, J. World Energy Assessment: Energy and the Challenge of Sustainability; United Nations: New York, NY, USA, 2000.

33. Ren21, Renewable Energy Policy Network for the 21st Century, Renewables 2014, Global Status Report. 2016. Available online: http:/ / www.ren21.net/status-of-renewables/global-status-report/ (accessed on 19 December 2017).

34. IEA-ETSAP and IRENA, Water Desalination Using Renewable Energy-Technology brief I12. March 2012. Available online: http:/ / www.irena.org/publications/2013/Jan/IRENA-IEA-ETSAP-Technology-Briefs (accessed on 19 December 2017).

35. Smaoui, M.; Krichen, L. Control, energy management and performance evaluation of desalination unit based renewable energies using a graphical user interface. Energy 2016, 114, 1187-1206. [CrossRef]

36. Hamilton, J.M.; Negnevitsky, M.; Wang, X.; Tavakoli, A.; Mueller-Stoffels, M. Utilization and Optimization of Diesel Generation for Maximum Renewable Energy Integration. In Green Energy and Technology; Springer: Berlin, Germany, 2017; pp. 21-70.

37. Nayar, C.V. High Renewable Energy Penetration Diesel Generator Systems. In Paths to Sustainable Energy; InTech: London, UK, 2010.

38. Ibrahim, H.; Ilinca, A.; Perron, J. Energy storage systems characteristics and comparisons. Renew. Sustain. Energy Rev. 2008, 12, 1221-1250. [CrossRef]

39. Società Elettrica Ponzese, Project for a New Diesel Power Plant. Available online: http://www. societaelettricaponzese.it/nuova-centrade-di-monte-pagliaro/ (accessed on 2 January 2018).

40. PVGIS-Geographical Assessment of Solar Resource and Performance of Photovoltaic Technology. Available online: http:/ / re.jrc.ec.europa.eu/pvgis / (accessed on 19 December 2017).

41. Corsini, A.; Marro, E.; Rispoli, F.; Tortora, E. Wave energy conversion potential from small scale systems in the Pontinian Archipelago. In Proceedings of the OWEMES 2009 Conference, Brindisi, Italy, 21-23 May 2009.

42. Corsini, A.; Marro, E.; Rispoli, F.; Tortora, E. Space-Time mapping of wave Energy conversion potential in Mediterranean Sea States. In Proceedings of the ASME-ATI-UIT 2010 Conference, Sorrento, Italy, 16-19 May 2010.

43. Corsini, A.; Tortora, E.; Cima, E. Preliminary assessment of wave energy use in an off-grid minor island desalination plant. Energy Procedia 2015, 82, 789-796. [CrossRef]

44. Cima, E.; (Acqualatina S.P.A., Italy). Personal Communication, 2017.

45. Drouilhet, S.; Shirazi, M. Wales, Alaska High-Penetration Wind-Diesel Hybrid Power System: Theory of Operation; Technical Report; Department of Energy Office of Scientific and Technical Information: Oak Ridge, TN, USA, 2002. [CrossRef]

46. British Columbia Government Official Web Site. Available online: https://www2.gov.bc.ca/assets/gov / environment/climate-change/data/provincial-inventory/2012/2012_emission-factors.xls (accessed on 19 December 2017).

47. Klein, S.A.; Beckam, W.A.; Mitchell, J.W.; Braun, J.E.; Evans, B.L.; Kummert, J.P. TRNSYS-A Transient System Simulation Program; Solar Energy Laboratory: Madison, WI, USA, 2000.

48. Colmenar-Santos, A.; Monzón-Alejandro, O.; Borge-Diez, D.; Castro-Gil, M. The impact of different grid regulatory scenarios on the development of renewable energy on islands: A comparative study and improvement proposals. Renew. Energy 2013, 60, 302-312. [CrossRef] 
49. Corsini, A.; Rispoli, F.; Tortora, E.; Gonella, M.; Piccini, M. Desalination performance of a concentrated solar power plant for energy and water production. In Proceedings of the 4th international Energy Conference, Ramallah, Palestine, 26-27 January 2011.

50. Corsini, A.; Tortora, E. The influence of water desalination systems on load levelling of gen-set in small off-grid islands. In Proceedings of the 9th International Conference on Applied Energy (ICAE2017), Cardiff, UK, 21-24 August 2017. 